\title{
CONCEPÇÕES SOBRE ALTAS HABILIDADES/SUPERDOTAÇÃO: REFLEXÕES COM BASE NA DISCURSIVIDADE DOCENTE
}

\author{
Jeanny Monteiro Urquiza* \\ Bárbara Amaral Martins**
}

\begin{abstract}
RESUMO: A categoria docente ainda se mostra inabilitada para atender, educacionalmente, as pessoas com altas habilidades/superdotação (AH/SD), visto que essa especificidade é pouco discutida nos âmbitos escolares, o que desencadeia muitas concepções mitológicas e preconceituosas a despeito desse alunado e de como atendê-lo. Diante deste cenário, ilustra-se cada vez mais o imperativo de conhecer o que pensam os professores sobre o referido fenômeno, pois os processos de identificação e de atendimento aos estudantes com indicadores de AH/SD perpassam, substancialmente, pelas ações docentes. Com base no exposto, esta pesquisa objetivou investigar as concepções sociais docentes sobre $\mathrm{AH} / \mathrm{SD}$, de maneira a analisarmos quais as premissas explicativas que fundamentaram essas representações. A amostra foi constituída por onze professores pertencentes à Educação Infantil, cujos depoimentos foram analisados segundo o método do Discurso do Sujeito Coletivo. Nos resultados, fizeram-se presentes concepções inverídicas; evidenciaram-se conceitos alinhados a Teoria dos Três Anéis e desvelaram-se conhecimentos superficiais quanto à temática investigada. Neste contexto, refletimos que tanto a formação inicial como a continuada deve discutir, com os professores, conhecimentos científicos sobre esta área, para que uma educação mais exitosa e comprometida com o desenvolvimento de potenciais seja efetivamente oferecida ao público com AH/SD.
\end{abstract}

PALAVRAS-CHAVE: Representações docentes; Discurso coletivo; Altas Habilidades/Superdotação.

\section{CONCEPTIONS ABOUT GIFTEDNESS: REFLECTIONS BASED ON TEACHING DISCOURSE}

\begin{abstract}
The teaching category is still unable to provide educational services to people with giftedness, as this specificity is rarely discussed in school settings, which triggers many mythological and prejudiced conceptions in spite of this student and how to serve them. In view of this scenario, it is imperative to know what teachers think about this phenomenon is increasingly illustrated, since the processes of identification and assistance to students with giftedness indicators substantially pass through the teaching actions. Based on the above, this research aimed to investigate teachers' social conceptions about giftedness, in order to analyze what are the explanatory premises that founded these representations. The sample consisted of eleven teachers belonging to Early Childhood Education, whose interviews were analyzed according to the Discourse of the Collective Subject method. In the results, untrue conceptions were present; concepts aligned with the three-ring theory were revealed and superficial knowledge about the investigated theme was revealed. In this context, we reflect that both initial and continuing education should discuss, with teachers, scientific knowledge about this area, so that a more successful education and committed to the development of potentials is effectively offered to the public with giftedness.
\end{abstract}

KEYWORDS: Teaching Representations; Collective Discourse; Giftedness.

\footnotetext{
* Mestra em Educação pelo Programa de Pós-Graduação em Educação do Campus do Pantanal, Universidade Federal de Mato Grosso do Sul (PPGE/CPAN/UFMS). Endereço eletrônico: urquiza.jeanny@gmail.com ORCID: https://orcid.org/0000-0003-3605-8266

** Doutora em Educação pela Universidade Estadual Paulista “Júlio de Mesquita Filho” (Unesp), Campus de Marília. Professora adjunta do Programa de Pós-Graduação em Educação do Campus do Pantanal, Universidade Federal de Mato Grosso do Sul (PPGE/CPAN/UFMS). Endereço eletrônico: barbara.martins@,ufms.br ORCID: https://orcid.org/0000-0003-4278-1661
} 


\section{Introdução ${ }^{1}$}

O fenômeno Altas Habilidades/Superdotação (AH/SD)² é caracterizado por indivíduos que apresentam comportamentos superiores, nos quais interagem três fatores: habilidade acima da média, comprometimento com a tarefa e criatividade; que não estão presentes, simultaneamente, no desenvolvimento, mas que se relacionam em algum momento para que um elevado nível de produtividade possa emergir, tal como propõe a Teoria dos Três Anéis, de Joseph Renzulli (2002).

Neste contexto, convém esclarecer que as $\mathrm{AH} / \mathrm{SD}$ não se configuram como temática recente na literatura científica, uma vez que há diversos estudos - inicialmente produzidos em âmbito internacional, que já se propunham a investigar as particularidades desta área, bem como as singularidades de sua população. Segundo as pesquisas de Martins (2020), o interesse pela educação de indivíduos pertencentes a este público se expressa, com maior intensidade, a partir da segunda metade do século XX, ainda com a emergência das primeiras instituições escolares que se destinavam, especificamente, ao processo educativo dessa parcela populacional.

Em referência à realidade brasileira, cumpre salientar que a produção acadêmica sobre AH/SD vem se ampliando significativamente, sobretudo, quando este fenômeno é investigado nas instituições atinentes à educação formal (contextos escolares e universitários). Todavia, os estudos de Pérez (2003; 2011), Brancher (2011), Guenther (2011; 2012), Manso (2012), Martins e Chacon (2016; 2018), Martins, Pedro e Ogeda (2016), Rangni, Massuda e Costa (2017), Marques e Costa (2018), Virgolim (2019) e Martins (2020) têm desvelado que muitas ambiências educacionais de nosso país pouco detêm conhecimentos sobre esta área ou sequer dispõem de informações científicas sobre AH/SD e, por isso, não são capazes de reconhecer a existência de pessoas com tais comportamentos nos próprios espaços de ensino em que se desenvolvem o processo educativo; corroborando ainda mais para a invisibilidade deste alunado e o não atendimento às suas necessidades.

Neste cenário, ilustra-se que o maior imperativo das instituições formais de educação consiste, fundamentalmente, em se apropriar da multiplicidade de conhecimentos sobre o tema AH/SD que se propala na ambiência acadêmica, de modo a refleti-lo e a discuti-lo principalmente com um dos principais agentes formativos responsáveis por consolidar a educação: a categoria docente, cujas ações pedagógicoeducativas ganham centralidade por serem capazes de mitigar o processo histórico de negligência que é

\footnotetext{
${ }^{1}$ O presente trabalho é oriundo de nossa dissertação de mestrado concluída no ano de 2020 e intitulada: Representações sociais sobre altas habilidades/superdotação: o que pensam os professores da educação infantil?

${ }^{2}$ Optamos por seguir a Política Nacional de Educação Especial na Perspectiva da Educação Inclusiva (2008), que adota a nomenclatura "altas habilidades/superdotação", embora o Decreto no 10.502, de 30 de setembro de 2020, que institui a Política Nacional de Educação Especial: Equitativa, Inclusiva e com Aprendizado ao Longo da Vida, assuma a terminologia "altas habilidades ou superdotação". Vale ainda destacar que, no momento de finalização desta pesquisa, o atual documento foi suspenso pelo ministro Dias Toffoli, do Supremo Tribunal Federal, que proferiu, em decisão liminar, ação direta de inconstitucionalidade. Nesse sentido, a Política Nacional de Educação Especial (2020) será ainda submetida a referendo do Plenário.
} 
vivenciado pela população com $\mathrm{AH} / \mathrm{SD}$, com vistas a lhe proporcionar propostas educativas condizentes às suas características e alinhadas, ainda, às suas necessidades; o que tende a facultar a este público o reconhecimento, bem como a visibilidade de suas capacidades.

Ressalta-se, neste contexto, a imprescindibilidade da função docente para que precisamente se efetivem os processos de identificação e de atendimento aos estudantes com AH/SD, visto que as ações da referida categoria exercem vitalidade para que abordagens identificadoras e propostas compromissadas com o atendimento obtenham êxito para este específico alunado, garantindo-lhe o direito de vivenciar uma educação que reconheça os seus potenciais e capacidades, enriquecendo-os e nutrindo-os com estimulações qualitativamente diversificadas. Com base nessa premissa, parte-se do pressuposto de que os professores podem ofertar proposições educativas mais sensíveis, significativas e comprometidas com o desenvolvimento destes estudantes, de modo a facilitar o seu processo de identificação e a contribuir com o atendimento educacional especializado (AEE), que é direito deste público.

Concordam com este raciocínio Machado e Stoltz (2018) e Lima e Moreira (2018), quando os estudos realizados por essas autoras advertem para a importância do trabalho pedagógico-educativo docente frente às $\mathrm{AH} / \mathrm{SD}$, que notavelmente incide nas ações de identificar, reconhecer e atender as potencialidades destes estudantes manifestadas em sala de aula. Ademais, os professores podem influir de maneira positiva na educação deste alunado, com a organização de estratégias pedagógicas que atendam às suas demandas de aprendizagem e aos seus anseios (LIMA; MOREIRA, 2018).

Nesse sentido, evidencia-se, nesta produção, a importância que a categoria docente assume para a consolidação de uma intervenção educacional respeitosa aos discentes que apresentam comportamentos com $\mathrm{AH} / \mathrm{SD}$, pois, uma vez dotada tanto de aparato teórico-científico eficaz sobre o tema, como ainda, consciente de estratégias operacionais que possibilitem uma educação mais prazerosa e compromissada com o desenvolvimento de capacidades, os educadores se tornam, incontestavelmente, protagonistas por nutrir todos os tipos de habilidades manifestadas em ambientes escolares, sobremaneira, aquelas que demonstram desempenho superior quando analisadas em comparação à média dos demais. Há que se considerar, assim, a urgente necessidade de uma ação predecessora: compreender o que pensam os professores das escolas regulares no que tange ao fenômeno AH/SD, para que as propostas interventivas voltadas à identificação e ao atendimento sejam mais exitosas quanto à sua efetivação.

Refletir sobre as concepções docentes constitui-se como ação substancial para se verificar quais conhecimentos constituem a bagagem teórico-prática que orienta a filosofia de atuação profissional dos professores, além desta ação permitir a análise de como estes compreendem a manifestação de capacidades elevadas nos contextos educacionais e qual importância atribuem a essas especificidades, pois a nutrição dessas características depende, essencialmente, do trabalho pedagógico-educativo que é realizado pelo professor. Por conseguinte, salienta-se a necessidade de estudos científicos que assumam o objetivo de investigar o que pensa a categoria docente sobre o fenômeno $\mathrm{AH} / \mathrm{SD}$, pois, mais do que 
contribuir para com esta área, trata-se, também, de atribuir relevância social a estes profissionais e à sua atuação, considerando-a indispensável ao desenvolvimento integral da pessoa que pertence à parcela populacional com AH/SD.

Em razão disso, a pesquisa se ancora na problemática das representações sociais de professores sobre o referido fenômeno, de modo a entender, por representações, um conjunto de valores, ideias, concepções e práticas que permitem as pessoas se orientar em suas ações cotidianas (DUVEEN, 2015). Interessa-nos, logo, o campo representacional das concepções, que, tratando-se especificamente dos professores, configuram-se como alguns dos aspectos condutores da prática pedagógica. Neste prisma, assumimos o objetivo de investigar as concepções sociais docentes sobre AH/SD, de maneira a analisarmos quais as premissas explicativas que fundamentaram essas representações.

Ainda selecionamos, como lócus para o desenvolvimento deste estudo, os ambientes de aprendizagem pré-escolares da Educação Infantil, com vistas a analisarmos o que pensam os professores desse nível de ensino a respeito do fenômeno $\mathrm{AH} / \mathrm{SD}$, uma vez que é nesta etapa educativa que as habilidades superiores precocemente manifestadas pelas crianças podem ser adequadamente nutridas e estimuladas, de modo a garantir-lhes uma formação mais prazerosa, sensível e condizente com as suas necessidades e interesses. A investigação das concepções docentes sobre AH/SD ainda revela a sua importância por outro viés: o de colaborar para a desconstrução de conceitos mitológicos sobre a referida área, cujas bases existenciais encontram origem em representações sociais erroneamente constituídas a respeito deste fenômeno e de seu público.

Nesta direção, Manso (2012) reflete que pesquisas que apresentam a finalidade de compreender as concepções docentes sobre AH/SD são extremamente significativas, uma vez que podem fornecer uma compreensão mais aclarada sobre a importância que os contextos formais de educação atribuem a este específico fenômeno e a sua população. Além disso, há que se considerar, também, que a preocupação educacional com esse campo (e com outros que ainda se constituem como grupos minoritários da educação), encaminha-se cada vez mais para a proposta de educação inclusiva movimento pedagógico, político, cultural e social que se fundamenta no paradigma da diversidade humana para que os processos educativos se desenvolvam proficientemente, de modo com que a própria sociedade seja capaz de reconhecer e valorizar as diferenças, como também singularidades inerentes a cada sujeito (BRASIL, 2001).

Com base no exposto, este estudo se fundamenta no entendimento de que a categoria docente pode ser proficiente ao facilitar a identificação de estudantes com comportamentos de AH/SD, reconhecer a sua diversidade, valorizar as suas capacidades elevadas e fomentar proposições educativas que lhes desenvolvam os potenciais; de maneira com que o princípio de valorização à heterogeneidade humana se consolide genuinamente nas instituições escolares. 


\section{O que revelam as pesquisas brasileiras que investigam as concepções docentes sobre altas}

\section{habilidades/superdotação?}

Realizou-se a revisão de literatura sobre as concepções docentes acerca do fenômeno AH/SD, junto às publicações contidas nos sistemas de informação que integram a Biblioteca Digital Brasileira de Teses e Dissertações (BDTD), o catálogo de teses e dissertações da Coordenação de Aperfeiçoamento de Pessoal de Nível Superior (CAPES), a biblioteca eletrônica que compõe a Scientific Electronic Library Online (SciELO) e o Portal de Periódicos Eletrônicos de Psicologia (PePSIC), com a utilização dos seguintes descritores: concepções docentes; altas habilidades; superdotação; percepções docentes.

Por conseguinte, esta investigação identificou a presença de 112 produções que, genericamente, referiram-se aos descritores utilizados, porém, apenas cinco trabalhos objetivaram realmente investigar a referida temática, quatro dos quais dissertações e apenas um na modalidade de artigo acadêmico, cujas leituras se efetivaram por meio do resumo. Vale ressaltar, neste contexto, que apenas o Portal de Periódicos Eletrônicos de Psicologia (PePSIC) não apresentou nenhuma produção concernente às concepções docentes sobre o fenômeno AH/SD. No tocante às investigações recuperadas, ilustramo-las, cronologicamente, no quadro a seguir:

Quadro 1: Pesquisas sobre concepções docentes tocantes ao fenômeno AH/SD

\begin{tabular}{|c|c|c|}
\hline TíTULO & AUTOR(A)/ANO & LOCAL DE PRODUÇÃO \\
\hline $\begin{array}{c}\text { A percepção dos coordenadores de } \\
\text { licenciaturas da UEL sobre Altas } \\
\text { Habilidades/Superdotação }\end{array}$ & Cianca (2012) & $\begin{array}{c}\text { Universidade Estadual de Londrina } \\
\text { (UEL) }\end{array}$ \\
\hline $\begin{array}{c}\text { Concepções sobre Altas } \\
\text { Habilidades/Superdotação e } \\
\text { prática docente }\end{array}$ & Bahiense (2013) & Universidade Federal do Espírito \\
Santo (UFES) \\
\hline $\begin{array}{c}\text { Altas Habilidades/Superdotação } \\
\text { no contexto escolar: percepções de } \\
\text { professores e práticas docentes }\end{array}$ & Bahiense e Rossetti (2014) & Universidade Federal do Espírito \\
& & Santo (UFES) \\
\hline $\begin{array}{c}\text { O modelo de enriquecimento } \\
\text { escolar de Joseph Renzulli e o } \\
\text { atendimento educacional } \\
\text { especializado ao estudante com } \\
\text { Altas Habilidades/Superdotação: } \\
\text { percepções docentes }\end{array}$ & & Universidade Católica de Brasília \\
(UCB)
\end{tabular}

Fonte: Elaboração Própria. 
Diante do exposto, o estudo de Cianca (2012) estabeleceu o objetivo de identificar a percepção de docentes da educação superior sobre AH/SD, especificamente os coordenadores dos colegiados dos cursos de licenciatura da Universidade Estadual de Londrina (UEL). Participaram desta investigação, quatorze professores coordenadores e os resultados indicaram que a percepção desses profissionais sobre AH/SD ainda era elementar; de modo com que utilizavam acepções advindas do senso comum para refletirem sobre esse tema, além de não reconhecerem seus estudantes com potenciais para AH/SD. No tocante aos mitos, esta pesquisa indicou a existência de muitas concepções mitológicas, especialmente em relação às capacidades acima da média em áreas isoladas, às relações interpessoais, ao desajustamento psicológico, entre outras percepções docentes equivocadas.

A investigação de Bahiense (2013) apresentou, como objetivo, explorar as concepções de professores do Ensino Fundamental sobre $\mathrm{AH} / \mathrm{SD}$, que pertenciam à rede pública de educação do município de Vitória-ES. Nesse quadro, participaram deste estudo vinte professores das disciplinas escolares de Língua Portuguesa e de Matemática, cujo contexto de atuação profissional era o Ensino Fundamental II ( $6^{\circ}$ ano ao $9^{\circ}$ ano). Foram efetivadas entrevistas que abordavam sobre a conceituação do fenômeno $\mathrm{AH} / \mathrm{SD}$, a formação e prática profissional e os mitos relativos a esta área. Os resultados apontaram uma insatisfação docente quanto à sua preparação para o trabalho pedagógico-educativo com alunos pertencentes ao público com AH/SD, além de evidenciarem que a maior parcela dos educadores se pautava na crença de que as habilidades ou talentos estão presentes em algum grau nos indivíduos, mas que a ambiência social é importante para o desenvolvimento das potencialidades dessas pessoas, segundo a percepção dos respondentes.

O estudo de Bahiense e Rossetti (2014) também investigou as concepções de professores do Ensino Fundamental sobre AH/SD do município de Vitória-ES, de maneira a verificar a relação exercida entre essas concepções e a prática de atuação profissional dos participantes. Além disso, essa investigação avaliou o entendimento dos professores quanto à adequação de sua formação profissional para o trabalho pedagógico-educativo com pessoas que apresentam o comportamento de $\mathrm{AH} / \mathrm{SD}$, com vistas a observar as estratégias utilizadas pelos educadores para o processo de ensino-aprendizagem deste público. Os resultados indicaram que a categoria docente apresentou a concepção de que o estudante com AH/SD é requerente de atendimento especial, pois tem necessidades específicas. Além disso, a pesquisa revelou que os participantes não tiveram uma formação apropriada para atuarem com pessoas que apresentam o fenômeno AH/SD.

A produção de Coelho (2015), por sua vez, investigou as percepções de professores das Salas de Recursos no tocante ao atendimento e ao modelo de enriquecimento escolar proposto por Renzulli, além de averiguar os fatores teórico-metodológicos presentes na prática profissional dos participantes. Participaram desta pesquisa trinta professores, sendo que seis foram entrevistados e vinte e quatro responderam ao questionário. Os resultados deste estudo indicaram que as percepções docentes sobre o atendimento estiveram mais focalizadas em aspectos estruturais, do que em aspectos pedagógicos e de 
desenvolvimento do alunado com AH/SD. Os participantes demonstraram conhecimentos incipientes sobre o modelo de enriquecimento escolar. Sugeriu-se, finalmente, a necessidade de correlação entre a teoria, o referencial metodológico, o operacional e o subsídio legal para o atendimento especializado aos estudantes com AH/SD.

Por fim, a pesquisa de Silva (2017) identificou as concepções e práticas de professores da disciplina de Matemática, do Ensino Fundamental II ( $6^{\circ}$ ano ao $9^{\circ}$ ano), de três instituições diferentes: uma escola pública federal; uma escola pública distrital e uma escola da rede particular de ensino, sobre os estudantes com AH/SD. Foram entrevistados doze professores da referida área disciplinar e os resultados sugeriram que os educadores eram bastante qualificados, mas ainda desinformados sobre $\mathrm{AH} / \mathrm{SD}$, vez que as suas qualificações profissionais se direcionavam ao conhecimento relativo à Matemática. Além disso, as concepções docentes eram fundamentadas em entendimentos advindos do senso comum e da experiência individual. Isto posto, este estudo desvelará os caminhos metodológicos que permitiram a obtenção e análise dos dados.

\section{Método}

Esta pesquisa teve como participantes onze professores, cujo trabalho pedagógico-educativo se desenvolve na etapa de Educação Infantil. Constituíram-se, como lócus de estudo, cinco instituições educativas, sendo três atinentes aos municípios de Corumbá-MS e, respectivamente, duas pertencentes à cidade Ladário-MS.

O critério de seleção estabelecido por esta investigação centrou-se na atuação profissional apenas desenvolvida nos contextos educativos pré-escolares. Cumpre salientar que, ao público docente, dirigiram-se convites para a participação desta pesquisa.

Além disso, com os propósitos de preservar a identidade dos professores que compõem a amostra dessa investigação e de manter a confidencialidade das informações obtidas, nesta pesquisa optou-se pela adoção de nomes fictícios para os docentes participantes. Diante do exposto, o Quadro 2, a seguir, evidencia a caracterização dos professores que participaram desta investigação:

Quadro 2: Caracterização dos professores participantes

\begin{tabular}{|c|c|c|c|}
\hline PROFESSORES(AS) & IDADE & FORMAÇÃO & $\begin{array}{c}\text { TEMPO DE } \\
\text { ATUAÇÃO }\end{array}$ \\
\hline Letícia & 39 anos & Geografia e Pedagogia & 14 anos \\
\hline Vitória & 38 anos & Pedagogia & 11 anos \\
\hline Isabela & 39 anos & Pedagogia & 2 anos \\
\hline Cecília & 26 anos & Pedagogia & 3 meses \\
\hline Adriana & 37 anos & Pedagogia & 21 anos \\
\hline Pedro & 28 anos & Pedagogia & 6 anos \\
\hline Alice & 48 anos & Pedagogia & 27 anos \\
\hline Ana & 35 anos & Pedagogia & 6 meses \\
\hline Miguel & 50 anos & Pedagogia & 22 anos \\
\hline Francisca & 37 anos & Magistério & \\
\hline
\end{tabular}

Fonte: Elaboração própria. 
Verifica-se que a maioria dos professores é recém-integrante à profissão. A coleta de dados foi realizada tanto nas instituições educativas como nas residências dos participantes, conforme a disponibilidade de cada professor. Por conseguinte, para investigar as concepções desta categoria profissional sobre o fenômeno $\mathrm{AH} / \mathrm{SD}$, este estudo contemplou a utilização de roteiro. Cumpre ressaltar que os dados foram analisados qualitativamente.

Para a análise das informações obtidas tomou-se, como referencial, a proposta metodológica do Discurso do Sujeito Coletivo (DSC), cujo expoente é o pesquisador Fernando Lefèvre (2017). Assim, como o objeto de estudo elencado por esta pesquisa são as representações sociais docentes, este método é substancialmente dirigido para este campo e sua proposição consiste em viabilizar os estudos dos modos sociais de pensar para a obtenção das representações sociais - que estão presentes na atividade discursiva do sujeito, de modo a utilizá-los como ferramentas para a constituição de um pensamento coletivo (LEFÈVRE, 2017).

Segundo essa proposta metodológica, os discursos dos participantes são dotados de conteúdos, que, por sua vez, podem se reunir e representar pensamentos socialmente compartilhados. Deste modo, são essas fontes de conteúdos e argumentos que originam o nascimento de um "Sujeito Coletivo de Discurso" (LEFÈVRE, 2017), que se torna proficiente para dar “voz” às representações sociais extraídas da coletividade. Diante do exposto, convém esclarecer que o método do DSC é composto por cinco procedimentos para a análise das informações, que assim são elucidados por Lefèvre (2017):

a) $1^{a}$ etapa-obtenção de depoimentos: etapa crucial para o DSC, que depende de depoimentos autênticos, ricos e espontâneos para a constituição do pensamento coletivo;

b) $2^{a}$ etapa - redução do discurso: especificidade do DSC que requer a análise individual dos discursos para que o pesquisador capte, de cada depoimento, a essencialidade dos conteúdos. Os estratos mais significativos do discurso formam as Expressões-Chave (EC), que comporão o conteúdo do DSC;

c) $3^{a}$ etapa - busca do (s) sentido (s): ocorre após a extração das Expressões-Chave e consiste na verificação de um ou mais posicionamentos frente à pergunta proposta. Esta ação é denominada de Ideia Central (IC), que se trata de uma etiqueta semântica formulada pelo pesquisador para a identificação do(s) sentido(s) atribuído(s) pelo depoente. A IC pode ser composta por Ancoragens (AC), que são mecanismos em que o participante se ancora em conhecimentos preexistentes na sua bagagem social para dar sentido à pergunta proposta.

d) $4^{a}$ etapa - a categorização: reunião, em categorias, de discursos que apresentam Ideias Centrais semelhantes;

e) $5^{a}$ etapa - discurso do sujeito coletivo: momento final que reúne os conteúdos agrupados nas categorias para a formação de representações coletivas. O pesquisador fará uso da $1^{a}$ pessoa do singular para dar voz aos pensamentos coletivos; mas não se trata do "eu" do pesquisador, mas sim, refere-se ao "eu" construído para expressar as concepções coletivas. 
Em consonância com o exposto, este estudo se propôs a investigar três categorias: "Concepções docentes sobre Altas Habilidades/Superdotação"; "Concepções sobre os traços da Teoria dos Três Anéis" e, finalmente, a categoria "Conhecimento superficial", presente em grande parte da atividade discursiva dos professores.

\section{Resultados e Discussão}

De início, é importante mencionar que, para o processo de categorização, transcrevemos integralmente o conteúdo das entrevistas de todos(as) os(as) participantes, de maneira a identificarmos as Expressões-Chave em cada discurso, além de destacarmos as Ideias Centrais (e suas respectivas Ancoragens) com base nas próprias expressões. Neste prisma, reunimos e etiquetamos as Ideias Centrais com o mesmo valor semântico por meio de letras em caixa alta, comumente divididas em dois ou três grupos: A, B e C, tal como sugere a proposta metodológica do DSC (LEFÈVRE, 2017).

Deste modo, a primeira categoria que instituímos denomina-se "Concepções docentes sobre Altas Habilidades/Superdotação", que buscou investigar as representações sociais docentes a respeito dessa temática. Registramos todo esse processo de agrupamento no Quadro 3, a seguir:

Quadro 3: Categoria “Concepções docentes sobre Altas Habilidades/Superdotação" e suas Ideias Centrais

\begin{tabular}{|c|c|}
\hline $\begin{array}{l}\text { CATEGORIA - CONCEPÇÕES DOCENTES } \\
\text { SOBRE ALTAS HABILIDADES/SUPERDOTAÇÃO }\end{array}$ & IDEIAS CENTRAIS \\
\hline Definições terminológicas $(\mathrm{A})$ & $\begin{array}{l}\text { - Inteligência; } \\
\text { - Criatividade; } \\
\text { - Genialidade; } \\
\text { - Rapidez; } \\
\text { - Raciocínio; } \\
\text { - Estímulo; } \\
\text { - Facilidade; } \\
\text { - Talento; } \\
\text { - Pré-disposição; } \\
\text { - Inteligência acima da média; } \\
\text { - Desafio; } \\
\text { - Conhecimento; } \\
\text { - Superação; } \\
\text { - Aptidão; } \\
\text { - Capacidade elevada; } \\
\text { - Capacidade desenvolvida; } \\
\text { - Compreensão; } \\
\text { - Atenção; } \\
\text { - Apreensão do conteúdo; } \\
\text { - Interação; } \\
\text { - Hiperatividade. }\end{array}$ \\
\hline $\begin{array}{l}\text { Representações pautadas } \\
\text { Autossuficiência }(\mathrm{B})\end{array}$ & $\begin{array}{l}\text { - Não há nada o que ensinar para a criança, pois ela sabe } \\
\text { tudo; } \\
\text { - Tenta-se ensinar a ela escrever o nome e os numerais, mas } \\
\text { ela já sabe; } \\
\text { - Os conteúdos e as atividades já não são suficientes para a } \\
\text { criança estar ali; } \\
\text { - Faz-se o "feedback" com o(a) aluno(a) e percebe-se que } \\
\text { ele(a) entendeu, ao ponto de não preocupar-se mais com }\end{array}$ \\
\hline
\end{tabular}




\begin{tabular}{|c|c|}
\hline & ele(a). \\
\hline $\begin{array}{l}\text { Potencialidade elevada acima dos demais pares da } \\
\text { mesma idade }(C)\end{array}$ & $\begin{array}{l}\text { - É uma criança que está além daquela turma; } \\
\text { - Ouvi falar de criança que já conseguiu entrar até na } \\
\text { Universidade; } \\
\text { - Criança que tem uma facilidade para aprender, que a } \\
\text { coloca além do nível que ela está; } \\
\text { - Demonstra talento e comportamento mais habilidoso; } \\
\text { - A criança consegue ir além daquilo que você espera para a } \\
\text { idade dela, de modo a praticar e a fazer coisas inesperadas; } \\
\text { - É uma criança que apresenta uma facilidade maior para } \\
\text { aprender o que a maioria da população não consegue } \\
\text { aprender; } \\
\text { - Essa criança vem com algo específico, diferenciado, na } \\
\text { forma dela aprender e se desenvolver; } \\
\text { - Apresenta facilidade maior que os outros para } \\
\text { compreender o conteúdo, a ponto de ser capaz de explica- } \\
\text { lo para os colegas. }\end{array}$ \\
\hline
\end{tabular}

Fonte: Elaboração Própria.

Nesse sentido, o DSC elaborado para essa categoria expressa conceitos e definições relacionados ao fenômeno $\mathrm{AH} / \mathrm{SD}$, com base nas representações extraídas dos depoimentos docentes. Diante do quadro dessas informações, elaboramos a seguinte proposta coletiva de discurso:

Eu acredito que as pessoas com AH/SD têm uma capacidade elevada para realizar determinadas tarefas, demonstrando talento e comportamento mais habilidoso. Quando eu penso em AH/SD, imagino que seja algo relacionado a várias características: predisposição; inteligência acima da média; criatividade; genialidade; raciocínio; estímulo; conhecimento; superação; aptidão; hiperatividade; atenção; talento; compreensão; rapidez; interação; facilidade; desafio; apreensão do conteúdo e, principalmente, capacidades elevadas e capacidades desenvolvidas. Agora, quando eu penso em crianças, acredito que elas vêm com algo específico, diferenciado, na forma delas aprenderem e se desenvolverem. Por isso, eu imagino que são crianças que têm uma facilidade maior para aprender o que a maioria da população não consegue, colocando-se além de sua turma e do próprio nível em que se encontram. Eu tento ensinar os conteúdos e atividades, mas eles já não são mais suficientes para essas crianças que estão ali. Por exemplo, tento ensinar a ler e a escrever, mas, elas já sabem; então não há nada para ensinar a essas crianças, pois sabem tudo. Posso ainda falar que são crianças que conseguem ir além do que eu espero para a idade delas porque praticam e fazem coisas inesperadas. Elas compreendem o conteúdo ao ponto de serem capazes de explicá-lo para os colegas e, quando eu faço o 'feedback', percebo que elas entenderam o assunto e não me preocupo mais com elas. Olha, eu já ouvi falar de crianças assim que conseguiram entrar até na Universidade.

Diante dessa atividade discursiva, é importante refletirmos sobre algumas circunstâncias que a compõem. A primeira delas notoriamente refere-se à representação de que o público com AH/SD possui capacidades elevadas para a realização de "determinadas tarefas e/ou atividades", contrapondo-se ao depoimento posteriormente relatado de que "não há nada para ensinar" as crianças pertencentes a esta população, pois elas “já sabem tudo”. Tal ambiguidade se justifica em razão de este fenômeno ainda ser envolto por concepções estereotipadas, mitológicas, imprecisas e frequentemente desvencilhadas das discussões científicas que o definem, tal como aponta a literatura específica desta área, ainda composta pelos estudos de Pérez (2003), Guenther (2011), Manso (2012), Rangni, Massuda e Costa (2017), Marques e Costa (2018) e Martins (2020). 
Ainda nesse discurso, verificamos substancialmente presente o mito da "superdotação global". Ao discuti-lo, Winner (1998) pondera que é errôneo o entendimento de que as crianças com AH/SD possuem capacidades elevadas em todas as áreas. Observamos que esta interpretação ainda se faz atual no imaginário popular, sobretudo, nas representações docentes, o que requer discussões e estudos sobre essas crianças para que, verdadeiramente, emerja a concepção de que as habilidades superiores podem se destacar em apenas algumas áreas e não em todas, como foi dito nas reflexões iniciais desse coletivo. É nesta direção que a Política Nacional de Educação Especial na perspectiva da Educação Inclusiva (BRASIL, 2008) contribui para desmitificar essa representação socialmente arraigada, ao definir que os(as) estudantes com AH/SD demonstram potencialidades elevadas em áreas que podem ser isoladas ou combinadas, o que contribui para a desconstrução de que AH/SD se trata de um fenômeno global. Por outro lado, é importante complementar que a superdotação global existe, porém se trata de uma exceção (WINNER, 1998).

O segundo argumento relatado por essa coletividade que é passível de reflexões, refere-se à associação das AH/SD com os termos "genialidade" e "hiperatividade". No tocante à primeira expressão, Pérez (2003) reflete que a representação sobre essa área associada à genialidade converge equivocadamente ao pensamento de que essas pessoas são capazes de realizar apenas ações prodigiosas e/ou extraordinárias. Esta compreensão ainda está enraizada no entendimento de que essa população apresenta um desempenho acadêmico excepcionalmente elevado, de maneira a se pressupor que a incidência das AH/SD é rara na sociedade e nos contextos escolares, concepções que servem de “justificativa” à genialidade. Convém esclarecer que esta expressão se trata de uma gradação deste fenômeno, mas que apenas se refere às pessoas que contribuíram significativamente para a humanidade (WINNER, 1998), seja com concepções teóricas ou com inovações nos diversos setores sociais. É por isso que Brancher (2011) sinaliza a necessidade de dissociação entre AH/SD e genialidade, com vistas à desmitificação sobre as genuínas características de seu público.

Em referência à terminologia "hiperatividade", cumpre ressaltar que, frequentemente, estudantes com AH/SD são concebidos(as) como hiperativos(as) nos contextos educacionais pelo motivo de demonstrarem elevados níveis de energia; ações estrategistas para enfrentarem o tédio em sala de aula. Martins (2020) esclarece que esta crença decorre da ideia de que as capacidades elevadas se associam ao comportamento enérgico e aos altos níveis de atividade; características sujeitas à interpretação de que sejam indicadoras de hiperatividade. Mas, por outro lado, essa concepção desconsidera outra parcela de alunos(as) desta população: aqueles(as) que são tímidos(as) e/ou introspectivos(as), que tendem a não se manifestar quer seja pela vergonha, quer seja pela insegurança de serem expostos(as) ao julgamento preconceituoso de suas capacidades pela comunidade escolar. Ao refletirmos sobre esse(a) aluno(a), sobremaneira, as crianças que pertencem a essa população, não podemos excetuar os extremos bem como a diversidade de comportamentos que o próprio fenômeno pode ensejar. 
A terceira circunstância que compõe esse discurso coletivo reporta-se à crença de que AH/SD são comportamentos inatos, isto é, características inerentes ao sujeito desde o seu nascimento, tal como é verificável na afirmação de que as crianças desse público "vêm com algo específico". Trata-se de uma concepção que atribui certa naturalidade a esse fenômeno e ainda tende a desconsiderar as influências do ambiente social para o desenvolvimento de habilidades superiores. Winner (1998) elucida que este raciocínio decorre do senso comum, que tende a menosprezar a estimulação proveniente do meio social em razão exclusivamente da base genética. É ainda uma perspectiva que contrapõe essas duas necessidades, de modo a se inserir na categoria de mitos. Vale destacar que, para a emergência de comportamentos denotadores de $\mathrm{AH} / \mathrm{SD}$, faz-se necessária a correlação entre esses dois fatores: a predisposição biológica e os estímulos da ambiência social.

O quarto ponto presente em nossa discursividade coletiva se retrata a uma das principais concepções mitológicas que circunda o fenômeno AH/SD: o mito de autossuficiência, que está presente no entendimento de que os conteúdos e atividades "não são mais suficientes para as crianças que estão ali" porque elas "sabem tudo". Marques e Costa (2018) esclarecem que, entre as principais causalidades que historicamente se responsabilizam pela negligência a população de $\mathrm{AH} / \mathrm{SD}$, estão às representações relativas ao mito de autossuficiência sobre esses(as) estudantes no que se refere ao desempenho e à realização de suas atividades e tarefas.

Guenther (2011) clarifica que esta concepção considera que essas pessoas não são requerentes de estímulos, já que as suas produções se colocam acima da média. Mas, ao mesmo tempo, esta interpretação social e erroneamente posta é a responsável por marginalizar a educação destinada a esse público, que sente, como decorrência, as mazelas e insuficiências de processos educativos que os pressiona na acepção de igualá-lo ou padronizá-lo; sem ter suas habilidades sequer notadas ou potencializadas pelas instituições escolares. Martins e Chacon (2018) contribuem significativamente para essas reflexões ao expor que essa população pode tanto obter apoio para o desenvolvimento de suas capacidades e potencialidades como pode se frustrar diante de contextos escolares não desafiadores, que acabam se configurando como ambientes desestimulantes e desanimadores.

A última circunstância proveniente desse discurso coletivo se refere à afirmação docente de que não é preciso a preocupação com esse público nos contextos escolares, já que demonstrariam sempre a compreensão sobre determinado conteúdo ou assunto. Mais uma vez encontramos, nessa discursividade, o entendimento de que as pessoas com AH/SD são autossuficientes, isto é, que não dispõem de cuidados com a sua educação ou com a oferta de estímulos qualitativamente diversificados, visto que "sabem de tudo". Sobre isso, é importante refletirmos que, mais do que o acesso às escolas regulares, urgem discussões a respeito da permanência desse alunado nas instituições educativas, garantindo-lhes meios que possibilitem a vivência de uma educação que contemple as suas necessidades.

Com base no exposto, é importante refletirmos que especificidades dessa população demandam um atendimento diverso nos próprios contextos de educação regular e ainda consoante às características 
de cada indivíduo. Além disso, a garantia e efetividade dessas condições contemplam as disposições constitucionalmente previstas no Artigo 206, Inciso I, quando este versa sobre "a igualdade de condições para acesso e permanência na escola” (BRASIL, 1988). Deste modo, mais do que permitir a este público o acesso ao ensino regular brasileiro, torna-se um imperativo a oferta de estímulos que lhes assegurem a permanência adequada nas escolas, com a potencialização e enriquecimento de suas capacidades.

Brancher (2011) adverte sobre a importância de discussões centradas na reflexão sobre os aspectos conceituais que se relacionam ao fenômeno $\mathrm{AH} / \mathrm{SD}$, pois além de atuarem na não rotulação deste público ainda auxiliam a desconstrução de representações mitológicas sobre a sua população. Por isso, ponderamos que a reflexão sobre os conceitos tangentes a essa área pode facilitar, até mesmo, a emergência de instrumentos voltados à identificação, de modo a se traduzir em maiores oportunidades a essas pessoas; na estimulação conveniente de suas capacidades e, ainda, na vivência de experiências educacionais intencionalmente compromissadas com o enriquecimento de suas potencialidades.

De maneira a prosseguirmos com a ilustração das Ideias Centrais, optamos por apresentar a segunda categoria "Concepções sobre os traços da Teoria dos Três Anéis" de forma integrada e simultânea, vez que os traços de "Criatividade", "Habilidade acima da média" e "Comprometimento com a tarefa" se configuram como os três elementos da referida teoria. Por isso, requereu-se a seleção de palavras conceituais para cada elemento dessa proposição teórica. Neste contexto, esta categoria é dividida entre essas três características. É com base no exposto, que apresentamos o quadro que se segue:

Quadro 4: Categoria “Concepções sobre os traços da Teoria dos Três Anéis” e suas Ideias Centrais

\begin{tabular}{|c|c|}
\hline $\begin{array}{l}\text { CATEGORIA - CONCEPÇÕES SOBRE OS } \\
\text { TRAÇOS DA TEORIA DOS TRÊS ANÉIS }\end{array}$ & IDEIAS CENTRAIS \\
\hline Criatividade $(\mathrm{A})$ & $\begin{array}{l}\text { - Capacidade de surpreender; } \\
\text { - Imaginação; } \\
\text { - Força de vontade; } \\
\text { - Oportunidade; } \\
\text { - Arte; } \\
\text { - Experiências; } \\
\text { - Estímulos; } \\
\text { - Exposição de pensamentos; } \\
\text { - Criatividade; } \\
\text { - Liberdade; } \\
\text { - Humanidade; } \\
\text { - Criação mediante as adversidades; } \\
\text { - Talento; } \\
\text { - Invenção; } \\
\text { - Habilidade; } \\
\text { - Proatividade; } \\
\text { - Saber; } \\
\text { - Entender; } \\
\text { - Produzir; } \\
\text { - Ludicidade. }\end{array}$ \\
\hline Habilidade acima da média (B) & $\begin{array}{l}\text { - Habilidades inesperadas; } \\
\text { - Capacidade de surpreender; } \\
\text { - Pessoas que são "CDFs"; } \\
\text { - Estímulos; } \\
\text { - Desenvolvimento precoce; } \\
\text { - Talento; }\end{array}$ \\
\hline
\end{tabular}




\begin{tabular}{|c|c|}
\hline & $\begin{array}{l}\text { - Destreza; } \\
\text { - Raciocínio; } \\
\text { - Realização de tarefas em tempo menor; } \\
\text { - Maior facilidade do que a maioria das pessoas apresenta; } \\
\text { - Inteligência; } \\
\text { - Criatividade; } \\
\text { - Apreensão; } \\
\text { - Conceito; } \\
\text { - Dinamicidade. }\end{array}$ \\
\hline Comprometimento com a tarefa $(\mathrm{C})$ & $\begin{array}{l}\text { - Responsabilidade; } \\
\text { - Interesse; } \\
\text { - Estímulo; } \\
\text { - Assiduidade; } \\
\text { - Compromisso; } \\
\text { - Persistência; } \\
\text { - Resiliência; } \\
\text { - Querer aprender; } \\
\text { - Dedicação; } \\
\text { - Concentração; } \\
\text { - Disciplina; } \\
\text { - Conhecimento; } \\
\text { - Atenção. }\end{array}$ \\
\hline
\end{tabular}

Fonte: Elaboração Própria.

O DSC da categoria “Concepções sobre os traços da Teoria dos Três Anéis” reúne representações sobre os fatores basilares dessa teoria: a criatividade, a habilidade acima da média e o comprometimento com a tarefa. É um discurso integrado que apresenta a seleção de várias palavras para caracterizar os fatores componentes dessa perspectiva teórica. Diante disso, apresentamos o DSC abaixo:

Acho que a 'criatividade' seria a capacidade de surpreender, fazer além do que você espera. É a imaginação, a força de vontade, a exposição de pensamentos. É a oportunidade e a criação mediante as adversidades, invenção, talento e proatividade. A criatividade se relaciona à arte, à humanidade, aos estímulos, à liberdade, às experiências, à ludicidade e à própria criatividade. É a habilidade de saber, entender e produzir. Por outro lado, eu entendo que a 'habilidade acima da média' tem a ver com habilidades inesperadas, com a capacidade de surpreender. São pessoas que são 'CDFs', apresentam desenvolvimento precoce, realizam tarefas em tempo menor e com mais facilidade do que a maioria das pessoas apresenta. No meu entendimento, a habilidade acima da média se envolve com o conceito, o estímulo, o talento, a destreza, a inteligência e a criatividade. A pessoa é dinâmica e tem uma maior capacidade de apreensão. Por fim, eu acho que o 'comprometimento com a tarefa' é uma série de coisas: responsabilidade, compromisso, interesse, disciplina, dedicação, concentração, estímulo, atenção e conhecimento. A pessoa quer aprender, é assídua, tem persistência e é resiliente.

O primeiro traço teórico evidenciado pelo discurso desse coletivo se trata da criatividade, definida pelas representações docentes como a "capacidade de surpreender" e fazer atividades "além do esperado”. Este entendimento se aproxima das definições do próprio Renzulli (2002), que compreende a criatividade como um traço que propicia às pessoas o reconhecimento de suas realizações criativas. Quando esse discurso apresenta o entendimento sobre esse aspecto como "oportunidade e criação mediante as adversidades", “invenção", "talento", "proatividade”, "arte”, "estímulos”, "experiências" e "ludicidade", ele está se referindo à capacidade que o sujeito possui de demonstrar originalidade e pensamento divergente; destoando-se de habilidades que seus pares apresentam. Por isso, a criatividade 
ainda é um componente que requer atenção quanto à sua identificação, já que testes psicométricos não são capazes de comprová-la. De acordo ainda com Renzulli (2002), faz-se necessário o uso de metodologias alternativas para avaliar a presença dessa manifestação.

O segundo traço da abordagem teórica em questão se refere à habilidade acima da média. Quando o discurso coletivo explicita que a pessoa é "dinâmica" e tem "uma maior capacidade de apreensão", observamos nesse entendimento representações concernentes à habilidade acima da média, especificamente, à habilidade geral de "engajamento em pensamento abstrato" (RENZULLI, 2002, p. 71, tradução nossa). Outra característica marcante nessa discursividade é a compreensão coletiva de que o público com AH/SD é composto por pessoas "CDFs". Marques e Costa (2018) esclarecem que essa e outras terminologias se tratam de termos discriminatórios e preconceituosos, que tendem a rotular essa população justamente por ela ter habilidades destoantes das demais pessoas. Vale destacar, neste contexto, que se constitui como um imperativo a superação de terminologias depreciativas; para que se possa fortalecer a construção identitária deste público e para que ele desenvolva uma percepção social positiva sobre as suas próprias características.

Por fim, o último traço da Teoria dos Três Anéis que está presente nas contribuições discursivas analisadas é o comprometimento com a tarefa. Muitas terminologias que constituem as representações docentes se aproximaram deste componente teórico, que representa, ainda, a energia empregada para a solução de algum problema (ou tarefa) em um específico campo de domínio (RENZULLI, 2002). Quando esse discurso coletivo utiliza os termos "disciplina" e "dedicação", está se direcionando a característica de "trabalho árduo" apontada por Renzulli (2002). As terminologias "compromisso", “interesse", "concentração" e "atenção" se relacionam, intrinsecamente, à capacidade que a pessoa com AH/SD tem de se envolver em algum trabalho importante (RENZULLI, 2002). Por fim, os termos "persistência" e "resiliente" indicam proximidade com as características de "perseverança" e “resistência", sinalizadas pelo referido autor (RENZULLI, 2002).

A última categoria que integra esta investigação denomina-se "Conhecimento superficial" e expressa tanto as hesitações como a superficialidade quanto ao fenômeno AH/SD e seus questionamentos circundantes. Por isso, é uma categorização que apresenta essas divisões em sua organização, já que revela certa insegurança da categoria docente quanto ao fenômeno refletido. Reunimos as informações concernentes a esta subcategoria no quadro abaixo:

Quadro 5: Categoria "Conhecimento superficial" e suas Ideias Centrais

\begin{tabular}{|l|l|}
\hline CATEGORIA - CONHECIMENTO SUPERFICIAL & \multicolumn{1}{|c|}{ IDEIAS CENTRAIS } \\
\hline Hesitações (A) & - Conheço pouco, muito pouco; \\
& - A gente já ouviu falar sobre isso; \\
& - É complicado falar sobre esse tema; \\
& - Olha, é difícil dizer por que eu nunca tive um (a) aluno (a) \\
\hline
\end{tabular}

\footnotetext{
${ }^{3}$ A locução nominal representada pela sigla "CDF” é uma expressão muito utilizada pelo senso comum e significa uma pessoa que possui "crânio de ferro". É um conceito depreciativo que se cristalizou no meio social para referenciar as pessoas que apresentam maiores habilidades em uma área específica, mas atribuindo-lhes sentido negativo.
} 


\begin{tabular}{|c|c|}
\hline & $\begin{array}{l}\text { assim; } \\
\text { - Não sei nem como eu posso falar; } \\
\text { - Eu acho que é isso, não sei se está certo; } \\
\text { - Eu estou falando alguma besteira? } \\
\text { - Seria mais ou menos isso? } \\
\text { - Posso pular essa pergunta? } \\
\text { - Puxa, não sei te responder assim; } \\
\text { - Acho que estou sendo repetitiva (o) demais; } \\
\text { - Hoje está difícil de pensar; } \\
\text { - Eu não sou criativa (o)... então vou dizer o que? } \\
\text { - Para ser sincera (o), eu nunca vi uma criança superdotada } \\
\text { para ver o seu comportamento; } \\
\text { - Muito difícil falar de um assunto que a gente não sabe; } \\
\text { - Pode não ser o correto, mas é o que eu entendo. }\end{array}$ \\
\hline Superficialidade (B) & $\begin{array}{l}\text { - Já ouvi algumas coisinhas na pós; } \\
\text { - Dei uma lida em algumas coisas sobre isso; } \\
\text { - Não sei. Vou falar a verdade; } \\
\text { - A gente lê superficialmente; } \\
\text { - Já ouvi falar um pouco sobre AH/SD; } \\
\text { - Só mesmo por internet eu sei; } \\
\text { - Já ouvi assim... coisas de teorias; } \\
\text { - Pelo pouco que eu tive acesso a esse tema; } \\
\text { - Eu já vi muito assim... principalmente na televisão; } \\
\text { - Posso falar a mesma resposta que eu coloquei? } \\
\text { - Eu acho que sim; } \\
\text { - Eu acho que não; } \\
\text { - Não tenho muita informação sobre o assunto; } \\
\text { - A gente quer lembrar as coisas relembrando os livros; } \\
\text { - Eu não me lembro exatamente de ter estudado essa área; } \\
\text { - Tive poucas leituras sobre o tema; } \\
\text { - Tenho uma visão superficial sobre isso; } \\
\text { - Depois que você sai da Universidade, o conhecimento vai } \\
\text { ficando escasso. }\end{array}$ \\
\hline
\end{tabular}

Fonte: Elaboração Própria.

O DSC da categoria "Conhecimento superficial” reúne concepções que expressam hesitações e superficialidade quanto à temática de AH/SD. Por se tratar de um campo de estudos ainda desconhecido da categoria docente investigada, as representações estão imbuídas de insegurança, medo, desconforto diante das respostas e, ainda, demonstram titubeações, indecisões e discursos superficiais. Diante desse quadro, apesentamos o DSC a seguir:

Já ouvi falar um pouco de AH/SD, li superficialmente, mas é complicado falar desse tema: então nem sei o que eu posso falar, tive pouco acesso a isso e nem sei se está certo. Dei uma lida em algumas coisas na pós, pela internet, já ouvi assim... coisas de teorias e já vi muito na televisão. Não tenho muita informação sobre o assunto e o que eu penso, pode não ser o correto, mas é o que eu entendo. Eu tento lembrar as coisas relembrando os livros, mas não me lembro de exatamente de ter estudado essa área. $\mathrm{O}$ que eu conheço é pouco, muito pouco; por isso tenho uma visão superficial. Acho que estou repetindo demais, não tenho criatividade. Então vou dizer o que? Será que eu estou falando alguma besteira? Posso falar a mesma coisa que eu coloquei? Seria mais ou menos isso ou posso pular a pergunta? Não sei, vou falar a verdade: sinceramente eu nunca tive uma criança superdotada para ver o seu comportamento. Puxa, eu não sei te responder assim porque eu nunca tive um(a) aluno(a) desse jeito. Além disso, depois que eu saí da Universidade, o conhecimento foi ficando escasso. Então é muito difícil falar de um assunto que eu não sei. 
O conhecimento superficial sobre AH/SD é decorrente de representações sociais obtusas, estereotipadas e imprecisas sobre esse fenômeno, que ainda se respaldam em mitos ou no próprio desconhecimento a respeito dessa temática. É neste contexto que Manso (2012) salienta a necessidade de os estudos se proporem a investigar o campo de concepções sobre AH/SD, especialmente, as representações docentes. Quando as contribuições discursivas dessa pesquisa sinalizam o entendimento de que "ouviram falar pouco", "leram superficialmente" ou que tiveram pouco acesso a esse tema, há que se ter claro que vamos ter representações de teor essencialmente mitológico, pois são concepções triviais que se distanciam do entendimento científico relativo a esse tema.

Entendemos que uma parte significativa desse conhecimento superficial ainda se mantém porque $\mathrm{AH} / \mathrm{SD}$ não se configuram como temática que é amplamente explorada pela sociedade e por seus veículos midiáticos, o que contribui para a prevalência de saberes superficiais. Diante do exposto, Martins e Chacon (2016) e Martins, Pedro e Ogeda (2016) apontam a negligência que a população com AH/SD sofre devido a sua não identificação, resultantes do desconhecimento sobre as especificidades de sua educação.

Marques e Costa (2018) também concordam com essas reflexões ao esclarecer que AH/SD não se constituem como temática recente, mas que ainda é desafiadora porque os(as) estudantes que apresentam esses comportamentos sempre foram, historicamente, negligenciados no que tange aos seus direitos educacionais. Acreditamos que grande parte dessa negligência decorre do desconhecimento ou da compreensão superficial sobre as suas características e sobre as especificidades de seu processo de educação. Neste contexto, analisamos que o discurso coletivo expresso acima é composto, em sua maioria, por representações superficiais quanto a nosso objeto de estudo e seu público, pois alguns(as) participantes apresentaram insegurança, medo e desconforto diante das respostas.

Ainda no que se refere ao conhecimento superficial, Pérez (2011) pondera que há "muitas pedras" presentes nos meandros específicos das AH/SD. Essas "pedras" nada mais são que empecilhos gerados pelo desconhecimento, pela ausência de formações e de informações científicas e, ainda, pelo preconceito que se faz presente na sociedade. Por isso, a autora reflete que esses empecilhos poderão ser removidos por meio do binômio saber-fazer e que esta correlação é incumbência de todos(as) quanto à sua concretização.

\section{Considerações Finais}

Muito há que se realizar em favor da efetivação de proposições educacionais voltadas ao desenvolvimento do público com $\mathrm{AH} / \mathrm{SD}$, que ainda é substancialmente negligenciado nos contextos escolares; quer pelo desconhecimento sobre as suas necessidades, quer pela existência de concepções estereotipadas sobre este grupo social bem como a sua formação. Diante desse quadro, esta pesquisa 
ilustrou a importância das ações didáticas de uma importante categoria profissional para a educação de pessoas pertencentes a esta população: a categoria docente, que pode se tornar proficiente na oferta de propostas educativas condizentes com as especificidades deste alunado e respeitadoras da diversidade que é inerente a cada ser humano, desde que os âmbitos de formação inicial e continuada discutam com os professores conhecimentos científicos sobre AH/SD.

Nesse sentido, refletimos que as limitações dessa pesquisa foram o número de participantes e a restrição geográfica. Por isso, sugerimos replicações em outros contextos e indicamos, como implicações para estudos futuros, a necessidade de mais produções acadêmicas compromissadas com o objetivo de investigar as representações sociais docentes sobre o tema; ação antecessora imprescindível a qualquer proposta educacional interventiva voltada ao público com AH/SD.

A partir de tudo que foi exposto, revela-se, portanto, a importância de os professores da rede regular de ensino constituir substrato teórico-prático que possibilite a identificação do alunado que apresenta o comportamento com AH/SD, visto que uma educação mais fruitiva, bem como a proposição de desenvolvimento integral à população com capacidades superiores poderá emergir a partir do momento em que a categoria docente constituir referencial teórico e operacional que conduza as suas ações educacionais, o que poderá se traduzir em inúmeros benefícios a este público à medida que as suas especificidades e demandas sejam atendidas com a devida atenção educacional e com mais proficiência, como requer qualquer estudante que integre a educação brasileira.

\section{REFERÊNCIAS}

BAHIENSE, Taisa Rodrigues Smarssaro. Concepções sobre Altas Habilidades/Superdotação e prática docente. 2013. Dissertação (Mestrado em Psicologia) - Universidade Federal do Espírito Santo, Vitória, 2013. Disponível em: http://repositorio.ufes.br/handle/10/3084. Acesso em 25 nov. 2020.

BAHIENSE, Taisa Rodrigues Smarssaro; ROSSETTI, Cláudia Broetto. Altas

Habilidades/Superdotação no contexto escolar: percepções de professores e prática docente. Rev.

Bras. Educ. Espec. [online], v. 20, n. 2, p. 195-208. 2014. Disponível

em: https://www.scielo.br/pdf/rbee/v20n2/04.pdf. Acesso em 25 nov. 2020.

BRANCHER, Vantoir Roberto. Altas Habilidades/Superdotação: diferentes conceitos e abordagens. In: BRANCHER, Vantoir Roberto; FREITAS, Soraia Napoleão. (Orgs). Altas

Habilidades/Superdotação: conversas e ensaios acadêmicos. Jundiaí: Paco Editorial, 2011. p. 13-31.

CIANCA, Fabiane Silva Chueire. A percepção dos coordenadores de licenciaturas da UEL sobre altas habilidades/superdotação. 2012. Dissertação (Mestrado em Educação) - Universidade Estadual de Londrina, Londrina, 2012. Disponível em: http://www.bibliotecadigital.uel.br/document/?code=vtls000180291. Acesso em 25 nov. 2020. 
COELHO, Ana Alves da Silva. O modelo de enriquecimento escolar de Joseph Renzulli e o atendimento educacional especializado ao estudante com Altas

Habilidades/Superdotação: percepções docentes. 2013. Dissertação (Mestrado em Educação) Universidade Católica de Brasília, Brasília, 2013. Disponível

em: https://bdtd.ucb.br:8443/ispui/bitstream/123456789/798/1/Ana $\% 20$ Alves $\% 20 d a \% 20 S i l v a \% 20 C$ oelho.pdf. Acesso em 25 nov. 2020.

DUVEEN, Gerard. Introdução: o poder das ideias. In: MOSCOVICI, Serge. Representações sociais: investigações em Psicologia Social. 11. ed. - Petrópolis, RJ: Vozes, 2015. p.7-28.

GUENTHER, Zenita Cunha. Caminhos para desenvolver potencial e talento. Lavras: Ed. UFLA, 2011.

GUENTHER, Zenita Cunha. Quem são os alunos dotados? Reconhecer dotação e talento na escola. In: MOREIRA, Laura Ceretta (coord.). Altas Habilidades/Superdotação, talento, dotação e educação. Curitiba: Juruá, 2012. p.63-81.

LEFÈVRE, Fernando. Discurso do Sujeito Coletivo: nossos modos de pensar, nosso eu coletivo. São Paulo: Andreoli, 2017.

LIMA, Denise Maria de Matos Pereira; MOREIRA, Laura Ceretta. O professor frente à identificação do estudante com Altas Habilidades/Superdotação na universidade. In: VIRGOLIM, Angela (org.). Altas Habilidades/superdotação: processos criativos, afetivos e desenvolvimento de potenciais. Curitiba: Juruá, 2018. p.271-286.

MACHADO, Járci Maria; STOLTZ, Tania. Aluno com Altas Habilidades/Superdotação matematicamente talentoso: um desafio ao professor. In: VIRGOLIM, Angela (org.). Altas

Habilidades/superdotação: processos criativos, afetivos e desenvolvimento de potenciais. Curitiba: Juruá, 2018. p.261-270.

MANSO, Renata Sayão Araújo. Concepções e mitos sobre superdotação: o que pensam professores de crianças pequenas?. 2012. Dissertação (Mestrado em Educação) - Universidade Católica de Brasília, Brasília, 2012. Disponível

em: https://bdtd.ucb.br:8443/jspui/bitstream/123456789/705/1/Renata $\% 20$ Sayao $\% 20$ Araujo $\% 20 \mathrm{Ma}$ nso.pdf. Acesso em 25 nov. 2020.

MARTINS, Bárbara Amaral; CHACON, Miguel Cláudio Moriel. Características de altas habilidades/superdotação em alunos precoces: um estudo de caso. Rev. Bras. Educ. Espec.

[online], v. 22, n. 2, p. 189-202. 2016. Disponível em: http://www.scielo.br/scielo.php?pid=S141365382016000200189\&script=sci abstract\&tlng=pt. Acesso em 25 nov. 2020.

MARTINS, Bárbara Amaral; PEDRO, Ketilin Mayra; OGEDA, Clarissa Marques Maria. Altas habilidades/superdotação: o que dizem as pesquisas sobre estas crianças invisíveis?. Psicologia escolar e educacional, v. 20, n. 3, p. 561-568, 2016. Disponível em: http://www.scielo.br/pdf/pee/v20n3/2175-3539-pee-20-03-00561.pdf. Acesso em 25 nov. 2020.

MARTINS, Bárbara Amaral; CHACON, Miguel Cláudio Moriel. Implicações do ambiente escolar para a precocidade: uma análise das situações de sala de aula. Perspectiva, Florianópolis, v. 36, n. 1, p. 172-193. 2018. Disponível em: https://periodicos.ufsc.br/index.php/perspectiva/article/view/2175795X.2018v36n1p172/pdf. Acesso em 25 nov. 2020.

MARTINS, Bárbara Amaral. Alunos precoces com indicadores de Altas

Habilidades/Superdotação: reconhecendo e favorecendo a precocidade em sala de aula. Curitiba: CRV, 2020. 
MARQUES, Danitiele Maria Calazans; COSTA, Maria da Piedade Resende da. Altas

Habilidades/Superdotação: a intervenção educacional na precocidade a partir da teoria das inteligências múltiplas. São Carlos: Pedro \& João Editores, 2018.

PÉREZ, Susana Graciela Pérez Barrera. Mitos e crenças sobre as pessoas com altas habilidades: alguns aspectos que dificultam o seu atendimento. Rev. Bras. Educ. Espec. [online], n. 22, p. 1-10.

2003. Disponível em: https://periodicos.ufsm.br/educacaoespecial/article/view/5004/3033. Acesso em 25 nov. 2020.

PÉREZ, Susana Graciela Pérez Barrera. Prefácio. In: BRANHCER, V. R.; FREITAS, S. N. (orgs). Altas Habilidades/Superdotação: conversas e ensaios acadêmicos. Jundiaí: Paco Editorial, 2011.

RANGNI, Rosemeire de Araújo; MASSUDA, Mayra Berto; COSTA, Maria da Piedade Resende da (orgs.). Altas habilidades/superdotação: temas para pesquisa e discussão. São Carlos: EdUFSCar, 2017.

RENZULLI, Joseph Salvatore. (2002). Emerging conceptions of giftedness: Building a bridge to the new century. Exceptionality, 10(2), 67-75. Disponível em: https://www.tandfonline.com/doi/abs/10.1207/S15327035EX1002 2. Acesso em 25 nov. 2020.

URQUIZA, Jeanny Monteiro. Representações sociais sobre altas habilidades/superdotação: o que pensam os professores da educação infantil? 2020. Dissertação (Mestrado em Educação) Universidade Federal de Mato Grosso do Sul, Corumbá, 2020. Disponível em:

https://ppgecpan.ufms.br/jeanny-monteiro-urquiza-representacoes-sociais-sobre-altas-habilidadessuperdotacao-o-que-pensam-os-professores-da-educacao-infantil/. Acesso em: 20 jan. 2021.

VIRGOLIM, Angela. Altas Habilidades/Superdotação: um diálogo pedagógico urgente. Curitiba: InterSaberes, 2019.

WINNER, Ellen. Crianças superdotadas: mitos e realidades. Porto Alegre: Artes Médicas, 1998. 